\title{
Experimental Investigation of Multi-Jet Air Impingement in Various Conditions and Analysis using Desirability based Response Surface Methodology
}

\author{
P. Chandramohan ${ }^{1 \dagger}$, S. N. Murugesan ${ }^{2}$ and S. Arivazhagan ${ }^{3}$ \\ ${ }^{1}$ Misrimal Navajee Munoth Jain Engineering College, Chennai, Tamilnadu, India \\ ${ }^{2}$ Rajalakshmi Engineering College, Chennai, Tamilnadu, India \\ ${ }^{3}$ St. Joseph's College of Engineering, Chennai, Tamilnadu, India \\ †Corresponding Author Email: drmpchandramohan@gmail.com
}

(Received March 24, 2020; accepted June 8, 2020)

\begin{abstract}
This experimental analysis encapsulates the influence of Reynolds number (Re), diameter of nozzle, height to diameter (H/D) ratio and position of nozzle such as in-line and staggered over the responses heat transfer coefficient, temperature and Nusselt number of a hot flat plate exposed to cooling by multi-jet air impingement. For this analysis, a $15 \times 10 \mathrm{~cm}$ flat plate is being heated using a heating coil having a heat flux of $7666.67 \mathrm{~W} / \mathrm{m}^{2}$ which is maintained as constant through entire experiment. An H/D ratio of 2D, 4D and 6D is considered along with pipe diameters of 4,6 and $8 \mathrm{~mm}$ and Reynolds number are changed between 18000 to 22000. Experimental design was performed with response surface methodology based central composite design. For all output responses, a quadratic model is chosen for analysis and a second order mathematical model is evolved for predicting with a higher $\mathrm{R}^{2}$ value. Desirability analysis is performed for multi-objective optimization and the optimum input parameters obtained are Reynolds no. of 20347, pipe diameter of $8 \mathrm{~mm}$, $\mathrm{H} / \mathrm{D}$ ratio of 2 and in-line nozzle position with the maximum heat transfer coefficient of $189.411 \mathrm{~W} / \mathrm{m}^{2} \mathrm{~K}$, Nusselt number of 28.8712 and minimum temperature of $56.983^{\circ} \mathrm{C}$. Optimum condition-based confirmation experiments result in enhanced Nusselt number and heat transfer coefficient.
\end{abstract}

Keywords: Jet impingement cooling; Heat transfer; Response surface methodology; Nusselt number; Staggered and inline position; Reynolds number.

\begin{tabular}{|c|c|c|c|}
\hline \multirow{3}{*}{$\begin{array}{l}\mathrm{h} \\
\mathrm{H} / \mathrm{D}\end{array}$} & \multicolumn{3}{|c|}{ NOMENCLATURE } \\
\hline & convective heat transfer coefficient & $\mathrm{k}_{\text {air }}$ & thermal conductivity of air \\
\hline & $\begin{array}{l}\text { ratio of jet-to-target distance to diameter of } \\
\text { the nozzle }\end{array}$ & $\begin{array}{l}\mathrm{Nu} \\
\mathrm{Re}\end{array}$ & $\begin{array}{l}\text { Nusselt number, dimensionles } \\
\text { Reynolds number }\end{array}$ \\
\hline TC & Heat Transfer Coefficient & & \\
\hline
\end{tabular}

\section{INTRODUCTION}

Impinging jets are extensively utilized in higher heat transfer applications for cooling purposes in various engineering fields such as tempering of glass and metals, heat reduction in microelectronic devices, drying of textiles and papers, gas turbine blades, aircraft deicing etc (Xu and Gadala 2006; Singh et al. 2013). Investigations are performed both numerically and experimentally for heat transfer improvement in internal flows in smooth and dimpled surfaces. Apart from single jet air impingement, multiple-air impingements are applied (Fenot et al. 2005; Hosain et al. 2014) over

smooth flat plates and roughed dimpled surfaces to improve rate of heat transfer. In aeronautics, cooling problems arises due to overheating gases from high temperature generated during combustion and in critical conditions, by using array of cold jets containing air are impinged on the walls to be cooled (Fechter et al. 2013; Caggese et al. 2013). In this case, the quantity of air required and the position of nozzles are optimized in such a way that effective cooling is achieved.

In most of the experiments, cooling jets are placed in arrays having stable rectangular inline patterns with span-wise or stream-wise spacing design. In 
few cases, experiments are performed with upstream of impinging array of jets (Martin 1977) having an initial cross-flow incorporating more impinging jets, its results are scanter and produce the velocity dispensations of rowing jets and cross flow jets are concluded (Huang et al. 1998). Convoluted examinations of multi-jets were analyzed by using a smaller number of nozzles (Zhu et al. 2014). Wang et al. (2012) conducted experiments under transient conditions, using multiple circular jets on an eccentric table to examine the heat transfer phenomena of stationary hot steel plate and developed a finite difference program, depending on inverse heat conduction model to manipulate convective heat transfer in local surface and their correlated temperatures. Sharif (2013) proposed a twin oblique impinging jets disparate for obtaining higher distribution of heat transfer on the sides of heated surface to overcome the variance in heat transfer rate around the impingement spot and residual parts of surface below the region of jet.

Husain et al. (2013) examined a heat sink impinged by a silicon-based micro-jet by investigating thermal characteristics and pressure-drop for incompressible stable and laminar flow considering staggered and parallel micro-jet arrangement of 16 impinging jets with 13 arrays of staggered showed the foremost performance amid the multifarious configurations examined. Negi and Pattamatta (2015) performed optimization of dimple shapes by incorporating Bezier polynomial formulation. Higher local Nusselt number values were exhibited by optimized dimple shape. Kim and Kim (2016) evaluated inline and staggered convex and concave configurations in an array of jet cooling and found that, impinging jet-dimple array with staggered convex configuration exhibited the highest Nusselt number and the staggered concave arrangement exhibited the lesser pressure drop, while the inline concave configuration exhibited the elevated drop in pressure. The value of $0.8 \mathrm{H} / \mathrm{D}$, produced both the best pressure drop and the best heat transfer performance. Meslem et al. (2013) studied the mass transfer of a circular nozzle for Re is 1360 and the distance between surface and jet is varied from 1 to 5 and notified that the mass transfer is elevated by 18\%. Brizzi et al. (2000) performed thermal and aerodynamic analysis of jets using visualization approaches and found the lines appears in boundary regions in between the different cells. Yang et al. (2013) considered numerical and experimental studies of cooling on impingement film cooling of reversed convection with and without fins and found that efficiency of multiple cooling elevated with escalate in ratio of blowing. Many researchers had performed work related to in-line and staggered arrangement of multi-jet air impingement cooling on heated flat plate (Tripathi and Singh, 2015; Zhang et al. (1997); Bahrampoury et al. (2009)). Apart from experimental investigations, numerical simulation (Chougule et al. 2011) of multiple air jet impingement on hot plate is carried out by most of the researchers to improve the heat transfer coefficient (Senthilkumar et al. 2012). Optimization is the process of identifying the best combination of selected input parameters for the considered objective of maximization and minimization (Senthilkumar et al. 2014a).

In this work, experimental investigation is performed with multi-jet cooling air impingement on flat plates, with nozzles placed in-line and staggered positions with pipe diameter change, Reynolds no. and H/D ratio (Sagot et al. 2008) for increase in Nusselt number and heat transfer coefficient and reduction in prevailing temperature using RSM. A second order prediction model is developed for measured output using multiple regression models (Senthilkumar and Tamizharasan 2015) and simultaneous optimization of all the outputs are carried out with the help of desirability analysis. Finally, an authorization test is also performed to test accuracy of adopted method.

\section{ExPERIMENTAL Procedure AND METHODOLOGY}

The procedure of the experiments and analysis to be performed in this work is shown in flow chart provided in Fig. 1.

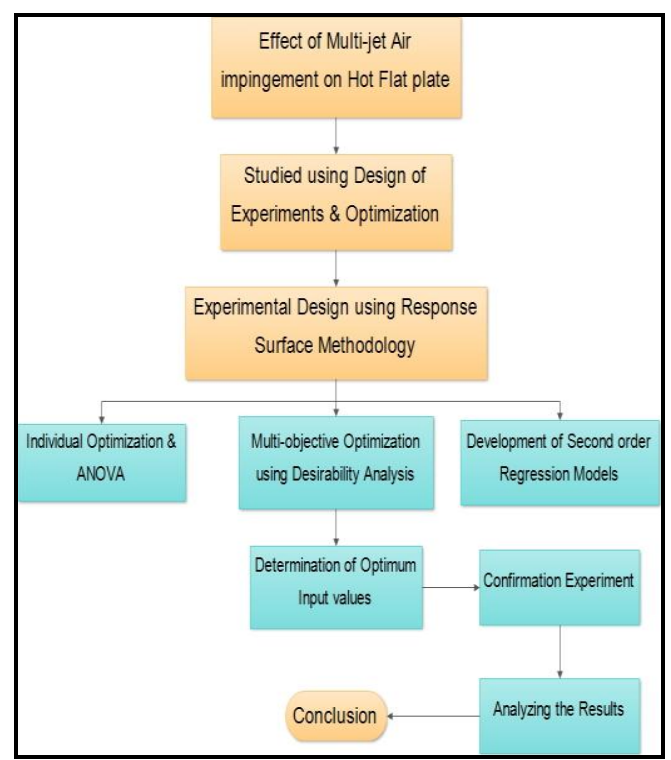

Fig. 1. Flowchart of the present work.

\subsection{Experimental Set-up}

The photographical view of experimentation considering hot plate with air impingement is illustrated in Fig. 2. A heating foil rectangular in shape $(150 \times 100 \mathrm{~mm})$ with 600 Watts is placed amid to plates of steel of similar size with $18 \mathrm{~mm}$ thickness and for varying the supply of heat, dimmerstat is used. For measuring temperature at surface, K-type thermocouples is placed (Chandramohan et al. 2017). A personnel computer with appropriate software and Agilent 34972A can simultaneously record airflow rate, the target plate temperature and air temperature. To avoid heat loss ceramic fiber of sufficient thickness is being used to cover all the face of plate except the top surface. Heating coil incorporated hot plates are placed on a stand. A lead screw arrangement is used to varying 


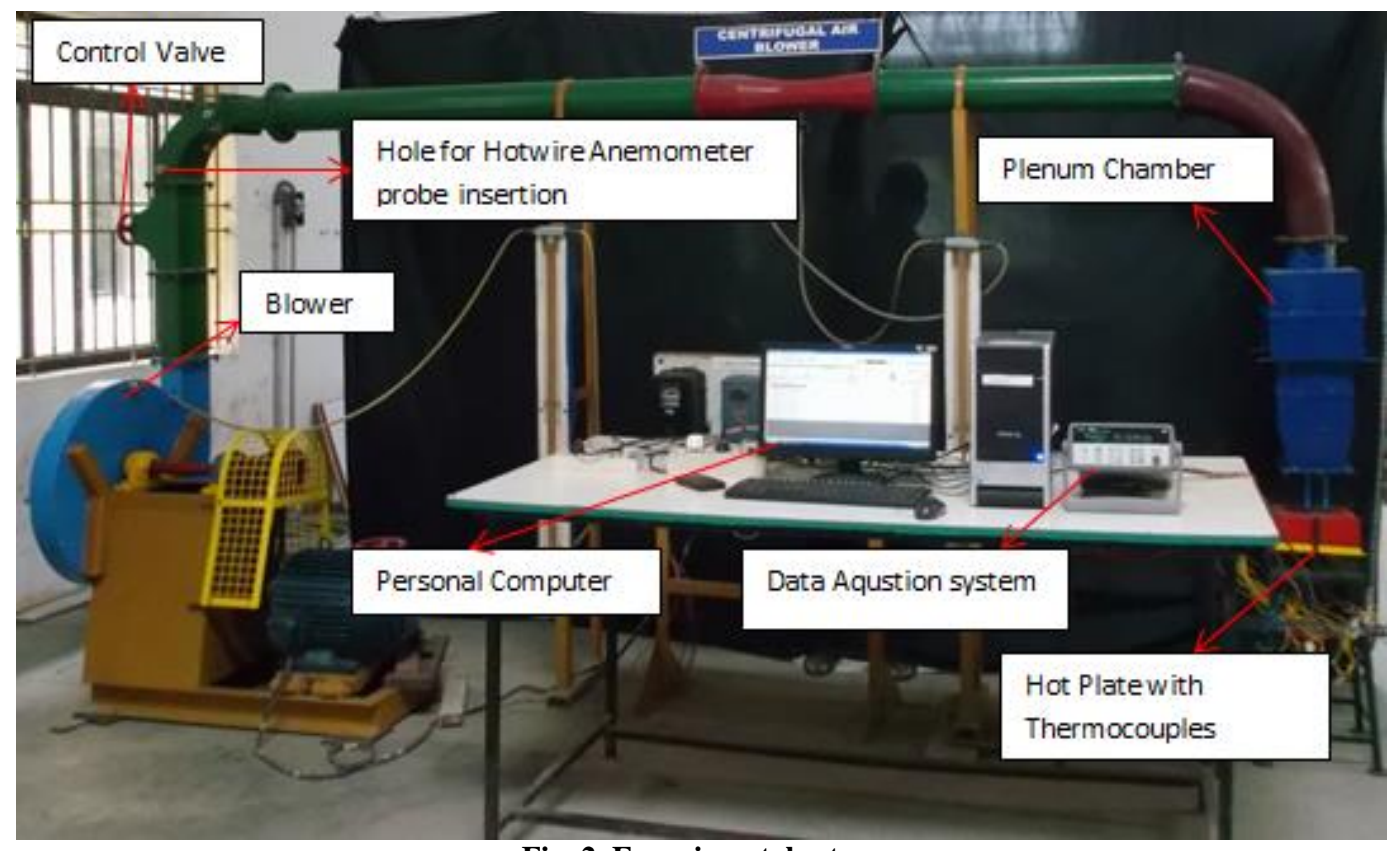

Fig. 2. Experimental setup.

the distance between the target surface and jet diameter. A centrifugal blower is used for supplying the required air to the air jet through plenum chamber.

In order to avoid fluctuation and make the flow stable and uniform, a plenum chamber is introduced before the air enters the nozzle.

For measuring air velocity, hot wire anemometer is placed in the air duct that carries blower air to nozzle through the plenum.

Usage of 3 configurations air jets such as 8,10 - and 12-mm diameter of nozzles for cooling the plates hot surface.

During fabrication, 15 number of thermocouples (K-type) are brazed through grooves on the bottom side of the top plate for computing the temperature at top surface of plate which is open to the air jets as shown in the Fig.3 and Fig.3 (a). A personal computer with data acquisition system is used to perceived the temperatures of thermocouples periodically and thus concluded the heat in the hot plate is uniformly distributed (Chandramohan et al. 2019).

The blower is switched on after attaching nozzle to plenum chamber and through a dimmer set (regulator) power supply is given to heating coil to supply a constant heat flux $\left(7666.67 \mathrm{~W} / \mathrm{m}^{2}\right)$ to the heating foil. Until the required Reynolds number is attained, air flow is regulated using control valve. A personal computer with data acquisition system is used to measure the temperatures at 15 points were observed periodically and after steady state is attained the final readings are notified for further manipulation. By changing Re from 18000 to 22000 and varying H/D from 2, 4 and 6, pipe diameter is varied between 4 to $8 \mathrm{~mm}$ and the position of nozzles is kept in-line and staggered to study its influence. The position of the nozzles in various places to study its impact in this present work for inline and staggered condition is presented in Fig. 4(a) and Fig. 4(b).

\subsection{Response Surface Methodology}

The main aim of Response Surface Methodology (RSM) is optimizing and analysis the problems by using a combined mathematic and statistical approach. Mostly in RSM, relationship type among independent variables and the response is unknown (Montgomery 2013; Senthilkumar et al. 2014 and Indira Priya et al. 2018). In RSM, foremost procedure is to determine an appropriate calculation of practical association among output response ' $y$ ' and independent variables ' $x$ '.

In the first-order model, the approximating function is evolved for a linear function of independent variables.

$y=\beta_{0}+\beta_{1} x_{1}+\beta_{2} x_{2}+\ldots+\beta_{k} x_{k}+\varepsilon$

The terms $\beta_{j}, j=0,1, k$, are coefficients of regression, with curvature presence in system, second order polynomial model is considered.

$y=\beta_{0}+\sum_{i=1}^{k} \beta_{i} x_{i}+\sum_{i=1}^{k} \beta_{i i} x_{i}^{2}+\sum_{i<j} \sum \beta_{i j} x_{i} x_{j}+\varepsilon$

Least square method is used for estimating the polynomial parameters and the fitted surface is obtained by using response surface analysis.

Analyzing the surface fitted be roughly alike to actual system analysis when the surface is acceptable estimate of true function of response. Identifying region of space factor, where operating conditions for the system requirements are fulfilled is the objective of RSM. In RSM various responses 
P. Chandramohan et al. / JAFM, Vol. 14, No. 1, pp. 131-145, 2021.

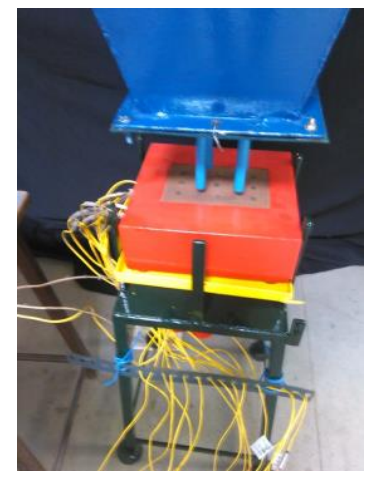

Fig. 3(a). Hot Plate with Thermocouples.

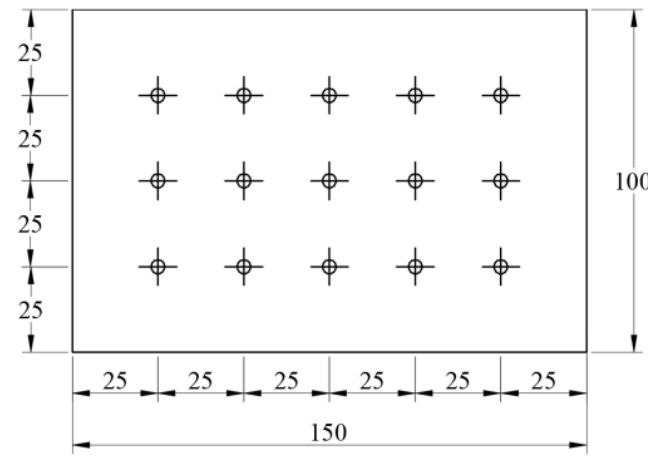

Fig. 3(b). Position of Thermocouples in the hot plate.

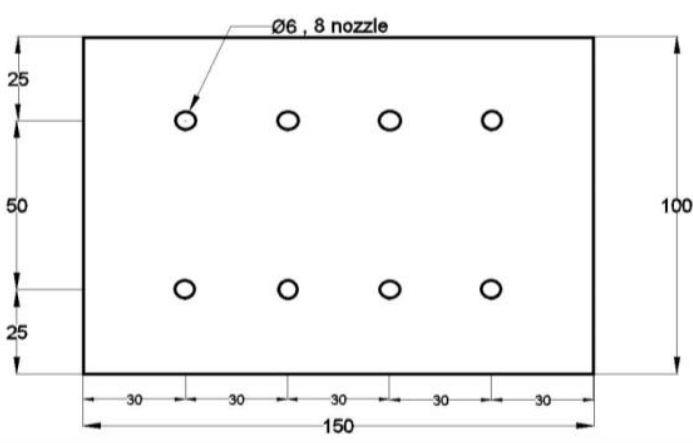

Fig. 4(a). Schematic Illustration of In-line position.

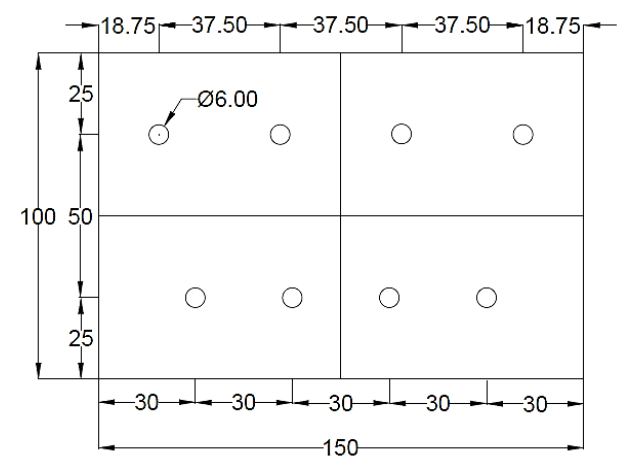

Fig. 4(b). Schematic Illustration of nozzle staggered nozzle position.

Table 1 Input parameters for Multi-jet Impingement cooling

\begin{tabular}{|c|c|c|c|c|}
\hline Parameter & Symbol & Units & -1 Level & +1 Level \\
\hline Reynolds No. & A & - & 18000 & 22000 \\
\hline Pipe Diameter & B & mm & 4 & 8 \\
\hline H/D Ratio & C & - & $2 \mathrm{D}$ & $6 \mathrm{D}$ \\
\hline Nozzle Position & D & - & Inline & Staggered \\
\hline
\end{tabular}

are analyzed. For each response consist of pertinent response surface model with multiple responses and then selecting a group of working conditions with desired ranges of all optimized responses. In this investigation, input parameters such as Re, pipe diameter, H/D ratio and nozzle position are considered. The various parametric values considered are shown in the Table 1.

In RSM, central composite design (CCD) approach, the authenticity of the Multi-jet Impingement cooling process is deliberate, which composes of a $2^{\mathrm{k}}$ factorial with $\mathrm{n}_{\mathrm{F}}$ runs, $\mathrm{n}_{\mathrm{c}}$ center runs and $2 \mathrm{k}$ axial runs. In face centered CCD design the alpha value is considered as 1 . Table 2 exposes the experimental design formulated for this study.

\section{RESULTS AND DISCUSSION}

In any experimental procedure a model can be developed relating the observed outputs to the chosen input parameters by the usage of multiple regression models, which might be used for prediction, process control or optimization. So to evaluate the outcome of multi-jet air infringement having inline and staggered setup, response surfaces were developed for outputs heat transfer coefficient, Nusselt number and temperature and ANOVA is performed for all the outputs to identify the most significant parameters. Finally, desirability analysis is carried out to optimize these all outputs simultaneously. 
Table 2 Face-centered CCD experimental matrix

\begin{tabular}{|c|c|c|c|c|}
\hline Run Order & Reynolds No. & Pipe Diameter (mm) & H/D Ratio & Nozzle Position \\
\hline 1 & 18000 & 6 & $4 \mathrm{D}$ & In-Line \\
\hline 2 & 20000 & 6 & $4 \mathrm{D}$ & In-Line \\
\hline 3 & 22000 & 8 & $2 \mathrm{D}$ & In-Line \\
\hline 4 & 22000 & 8 & $2 \mathrm{D}$ & Staggered \\
\hline 5 & 20000 & 4 & $4 \mathrm{D}$ & In-Line \\
\hline 6 & 20000 & 6 & $6 \mathrm{D}$ & Staggered \\
\hline 7 & 20000 & 6 & $4 \mathrm{D}$ & In-Line \\
\hline 8 & 22000 & 6 & $4 \mathrm{D}$ & In-Line \\
\hline 9 & 20000 & 6 & $4 \mathrm{D}$ & Staggered \\
\hline 10 & 20000 & 6 & $4 \mathrm{D}$ & Staggered \\
\hline 11 & 20000 & 6 & $4 \mathrm{D}$ & In-Line \\
\hline 12 & 18000 & 8 & $6 \mathrm{D}$ & Staggered \\
\hline 13 & 18000 & 8 & $6 \mathrm{D}$ & In-Line \\
\hline 14 & 20000 & 6 & $6 \mathrm{D}$ & In-Line \\
\hline 15 & 20000 & 6 & $4 \mathrm{D}$ & In-Line \\
\hline 16 & 20000 & 8 & $4 \mathrm{D}$ & In-Line \\
\hline 17 & 22000 & 4 & $6 \mathrm{D}$ & Staggered \\
\hline 18 & 18000 & 4 & $2 \mathrm{D}$ & In-Line \\
\hline 19 & 20000 & 6 & $4 \mathrm{D}$ & Staggered \\
\hline 20 & 22000 & 4 & $6 \mathrm{D}$ & In-Line \\
\hline 21 & 18000 & 6 & $4 \mathrm{D}$ & Staggered \\
\hline 22 & 20000 & 6 & $4 \mathrm{D}$ & In-Line \\
\hline 23 & 20000 & 4 & $4 \mathrm{D}$ & Staggered \\
\hline 24 & 20000 & 6 & $4 \mathrm{D}$ & Staggered \\
\hline 25 & 22000 & 6 & $4 \mathrm{D}$ & Staggered \\
\hline 26 & 20000 & 6 & $2 \mathrm{D}$ & Staggered \\
\hline 27 & 18000 & 4 & $2 \mathrm{D}$ & Staggered \\
\hline 28 & 20000 & 6 & $4 \mathrm{D}$ & Staggered \\
\hline 29 & 20000 & 8 & 4D & Staggered \\
\hline 30 & 20000 & 6 & $2 \mathrm{D}$ & In-Line \\
\hline
\end{tabular}

From the outcomes of the experimental investigation, as presented in Table 3, coefficient of heat transfer goes up with elevation in pipe diameter and increases in Reynolds no. up to 21000 , after which it gets settled out, but with increase in ratio of $\mathrm{H} / \mathrm{D}$, coefficient of heat transfer reduces. Temperature reduces with rise in pipe diameter and with increase in Reynolds no., temperature shoots up. With increase in H/D ratio, temperature further increases. With increase in pipe diameter a drastic increase in Nusselt no. is found and increasing Reynolds no, Nusselt no. increases. With decreasing H/D ratio, a considerable increase in Nusselt no. is observed. As predictable, peak pressure is maximum for higher Re. The non-dimensional value of peak pressure at region of stagnation for any Reynolds number and drops down radially as investigated by Srivalli et al. (2012). For inline position of nozzles, normalized heat transfer coefficient gets reduced. Drastic improvement in temperature is observed when the nozzle position is changed from inline to staggered. Normalized Nusselt no. is higher for inline position of nozzle with respect to staggered nozzle position.

During analysis of heat transfer coefficient, temperature and Nusselt number, quadratic model was suggested and chosen for analysis and also to develop the regression model. It is found from the
Analysis of Variance (ANOVA) tables that quadratic models are significant statistically and obviously the developed second order regression models represent true surface of chosen responses.

Performing ANOVA is a most important technique in order to analyze the out-turn of discrete inputs on an output. ANOVA, amongst the different factors disintegrate the variability in the response variable (Gamst et al., 2008). Depending on the sort of analysis, it might be significant to find out factors having influence on outputs and quantity of variation in outputs allocable to every factor (Senthilkumar et al. 2014b). For determining the influence of each parameter, ANOVA is performed.

Table 4 shows ANOVA for heat transfer coefficient which displays that the model is convincing. The most influencing parameter that contributes towards the response is position of nozzle i.e. whether in-line or staggered. With $95 \%$ confidence interval and with the value of $R^{2}$ is 0.951523 in good acceptances with the forecast $\mathrm{R}^{2}$ value is 0.835878 , this model developed is better for prediction and analysis. Values of $\mathrm{P}$ lower than 0.05 express that factors that are influential, pipe diameter, H/D ratio, and nozzle position, combined effect of Reynolds no. and H/D ratio and square term of Reynolds no. and pipe diameter. With $78.27 \%$ of 
contribution from nozzle position, it is the most influential parameter.

Table 3 Determined responses for analysis \begin{tabular}{|l|l|l|l|}
\hline Run & Heat Transfer & Nusselt \\
\hline
\end{tabular} Order Coefficient Temperature Number

\begin{tabular}{|c|c|c|c|}
\hline Order & Coefficient & & Number \\
\hline 1 & 156.378 & 63.03 & 22.3397 \\
\hline 2 & 162.091 & 71.76 & 22.9953 \\
\hline 3 & 169.546 & 70.03 & 28.7637 \\
\hline
\end{tabular}

\begin{tabular}{|l|l|l|l|}
\hline 4 & 136.793 & 69.37 & 27.2562 \\
\hline 5 & 167.451 & 79.69 & 22.4929 \\
\hline
\end{tabular}

\begin{tabular}{|l|l|l|l|}
\hline 6 & 125.875 & 77.15 & 21.4106 \\
\hline
\end{tabular}

\begin{tabular}{|l|l|l|l|}
\hline 7 & 161.144 & 72.17 & 22.7348 \\
\hline 8 & 159.426 & 93.73 & 23.6315 \\
\hline
\end{tabular}

\begin{tabular}{|l|l|l|l|}
\hline 9 & 141.142 & 77.84 & 21.5744 \\
\hline
\end{tabular}

\begin{tabular}{|l|l|l|l|}
\hline 10 & 140.067 & 75.95 & 21.2953 \\
\hline 11 & 161.827 & 72.62 & 22.4213 \\
\hline 12 & 127.226 & 69.76 & 27.4599 \\
\hline
\end{tabular}

\begin{tabular}{|l|l|l|l|}
\hline 13 & 155.141 & 62.28 & 28.1859 \\
\hline 14 & 156.227 & 78.07 & 21.3182 \\
\hline
\end{tabular}

\begin{tabular}{|l|l|l|l|}
\hline 15 & 161.351 & 71.97 & 22.5248 \\
\hline
\end{tabular}

\begin{tabular}{|l|l|l|l|}
\hline 16 & 185.096 & 71.29 & 28.6282 \\
\hline 17 & 132.165 & 88.75 & 20.0236 \\
\hline
\end{tabular}

\begin{tabular}{|l|l|l|l|}
18 & 132.165 & 88.75 & 20.0236 \\
\hline 18 & 158.295 & 58.01 & 26.4707 \\
\hline
\end{tabular}

\begin{tabular}{|l|l|l|l|}
\hline 19 & 141.742 & 76.52 & 21.6774 \\
\hline 20 & 165.563 & 91.61 & 18.2225 \\
\hline
\end{tabular}

\begin{tabular}{|l|l|l|l|}
\hline 21 & 123.135 & 70.11 & 21.0192 \\
\hline
\end{tabular}

\begin{tabular}{l|l|l|l}
22 & 160.942 & 72.45 & 23.2981 \\
\hline
\end{tabular}

\begin{tabular}{|l|l|l|l}
\hline 23 & 129.785 & 74.59 & 22.5406 \\
\hline 24 & 141.342 & 77.06 & 21.9833 \\
\hline
\end{tabular}

\begin{tabular}{|l|l|l|l|}
\hline 25 & 120.067 & 86.08 & 23.2953 \\
\hline 26 & 136.802 & 64.28 & 22.6859 \\
\hline
\end{tabular}

\begin{tabular}{|l|l|l|l|}
\hline 26 & 136.802 & 64.28 & 22.6859 \\
\hline 27 & 125.803 & 64.87 & 21.1147 \\
\hline 28 & 142.042 & 76.29 & 22.1426 \\
\hline 29 & 145.359 & 67.93 & 25.3375 \\
\hline 30 & 176.604 & 64.94 & 27.3721 \\
\hline
\end{tabular}

The residual plot of heat transfer coefficient, predicted vs. actual values and surface plots are shown in Fig. 5. It is inferred from the plot that remnant is spread close to the fitted unswerving line showing a fair correlation between the experimental and forecast values of the HTC and follows the normal distribution. The surface plot drawn between the Reynolds no. and pipe diameter shows that heat transfer coefficient varies exponentially with increase in Reynolds no. and increases linearly with increase in pipe diameter. Surface plot drawn in between Reynolds no. and H/D ratio shows a relationship between $\mathrm{H} / \mathrm{D}$ ratio and HTC.
For numerical optimization of heat transfer coefficient, higher the better concept is selected i.e. maximizing the response value for better heat removal. The optimum condition achieved is Reynolds No. of 21652, pipe diameter of $8 \mathrm{~mm}$; $\mathrm{H} / \mathrm{D}$ ratio is 2 and in-line nozzle position. The predicted value of heat transfer coefficient is $\mathbf{1 7 5 . 1 5}$ $\mathrm{W} / \mathrm{m}^{2} \mathrm{~K}$ with a desirability value of 0.879 , as shown in Fig. 6.

\subsection{Analysis of Temperature}

A significant model is developed as shown in Table 5 for ANOVA of temperature. The most influential parameters identified with $\mathrm{p}$ values less than 0.05 is Reynolds no., pipe diameter, H/D ratio, combined effect of Reynolds no. and nozzle position, pipe diameter and H/D ratio, square terms of Reynolds no. and H/D ratio. $26.39 \%$ contribution comes from Reynolds no. and H/D ratio contributes by $8.19 \%$. For minimizing temperature, the nozzle position contributes by less than $1 \%$. With $95 \%$ confidence interval and with the value of $\mathrm{R}^{2}$ is 0.9619 in good agreements with the forecast $\mathrm{R}^{2}$ value is 0.8155 , this model developed is better for prediction and analysis.

Fig. 7 shows the residual plot of temperature, predicted vs. actual values and surface plots. A good correlation is perceived between the prophesy values of temperature and experimental values from the plot between them and from residual plots, the residuals spread very nearer to the fitted straight line, following a normal distribution. The surface plot drawn between the Reynolds no. and pipe diameter shows that temperature varies linearly with elevation in Reynolds no. and also increases linearly with elevation in pipe diameter. Surface plot drawn in between Reynolds no. and H/D ratio shows a curvilinear, a non-linear relationship between $\mathrm{H} / \mathrm{D}$ ratio and temperature.

Lower the better (Minimize) option is selected during numerical optimization of temperature for better reduction in temperature. With that, the optimum condition achieved is Reynolds No. of 19617, pipe diameter of $7.9 \mathrm{~mm}, \mathrm{H} / \mathrm{D}$ ratio of 2.26 and in-line nozzle position. The predicted value of temperature is $53.97^{\circ} \mathrm{C}$ with a higher desirability value of 1, as presented in Fig. 8.

\subsection{Analysis of Nusselt Number}

From ANOVA shown in Table 6, a significant model is developed for Nusselt no. The significant parameters for Nusselt number are; all the input parameters considered and combined effect of Reynolds no. and H/D ratio, Reynolds no. and nozzle position, pipe diameter and H/D ratio and H/D ratio and nozzle position and square term of pipe diameter. Higher contribution is provided by the pipe diameter $(9.21 \%)$, $\mathrm{H} / \mathrm{D}$ ratio $(6.20 \%)$ and nozzle position $(6.52 \%)$, pipe diameter and H/D ratio $(4.99 \%)$ and square term of pipe diameter $(9.91 \%)$. It is clear that a considerable increase in Nusselt no. is obtained with change in nozzle position. With the chosen confidence interval of $95 \%$ and with the value of $\mathrm{R}^{2}$ is 0.966 in good accordance with the forecast $\mathrm{R}^{2}$ value is 0.7647 , this model developed is better for prediction and analysis. 
P. Chandramohan et al. / JAFM, Vol. 14, No. 1, pp. 131-145, 2021.

Table 4 ANOVA for Heat Transfer Coefficient

\begin{tabular}{|c|c|c|c|c|c|c|}
\hline Source & SS & Dof & MSS & F Value & Prob $>F$ & $\%$ Contribution \\
\hline Model & 8123.598 & 13 & 624.8922 & 24.1579 & $<0.0001$ & $95.15 \%$ \\
\hline A-Reynolds No. & 0.0001 & 1 & 0.0001 & $3.87 \mathrm{E}-06$ & 0.9985 & $0.00 \%$ \\
\hline B-Pipe Diameter & 275.8755 & 1 & 275.8755 & 10.66516 & 0.0049 & $3.23 \%$ \\
\hline C-H/D ratio & 244.9851 & 1 & 244.9851 & 9.470954 & 0.0072 & $2.87 \%$ \\
\hline D-Nozzle Position & 6682.281 & 1 & 6682.281 & 258.3323 & $<0.0001$ & $78.27 \%$ \\
\hline $\mathrm{AB}$ & 113.8223 & 1 & 113.8223 & 4.400291 & 0.0522 & $1.33 \%$ \\
\hline $\mathrm{AC}$ & 147.7981 & 1 & 147.7981 & 5.713774 & 0.0295 & $1.73 \%$ \\
\hline $\mathrm{AD}$ & 11.72163 & 1 & 11.72163 & 0.45315 & 0.5104 & $0.14 \%$ \\
\hline $\mathrm{BC}$ & 59.03834 & 1 & 59.03834 & 2.282381 & 0.1503 & $0.69 \%$ \\
\hline $\mathrm{BD}$ & 0.8274 & 1 & 0.8274 & 0.031987 & 0.8603 & $0.01 \%$ \\
\hline $\mathrm{CD}$ & 14.92316 & 1 & 14.92316 & 0.576919 & 0.4586 & $0.17 \%$ \\
\hline$A^{2}$ & 563.7011 & 1 & 563.7011 & 21.79229 & 0.0003 & $6.60 \%$ \\
\hline $\mathrm{B}^{2}$ & 241.1735 & 1 & 241.1735 & 9.3236 & 0.0076 & $2.82 \%$ \\
\hline $\mathrm{C}^{2}$ & 8.245931 & 1 & 8.245931 & 0.318782 & 0.5802 & $0.10 \%$ \\
\hline Residual & 413.8719 & 16 & 25.86699 & - & - & $4.85 \%$ \\
\hline Lack of Fit & 410.6721 & 8 & 51.33401 & 128.3428 & $<0.0001$ & $4.81 \%$ \\
\hline Pure Error & 3.199806 & 8 & 0.399976 & - & - & $0.04 \%$ \\
\hline Cor Total & 8537.47 & 29 & - & - & - & $100.00 \%$ \\
\hline Std. Dev. & 5.08596 & & $\mathrm{R}^{2}$ & 0.951523 & - & - \\
\hline Mean & 148.8809 & & Adjusted $\mathrm{R}^{2}$ & 0.912135 & - & - \\
\hline C.V. $\%$ & 3.416127 & & Predicted $\mathrm{R}^{2}$ & 0.835878 & - & - \\
\hline PRESS & 1401.188 & & Adeq Precision & 16.1341 & - & - \\
\hline
\end{tabular}

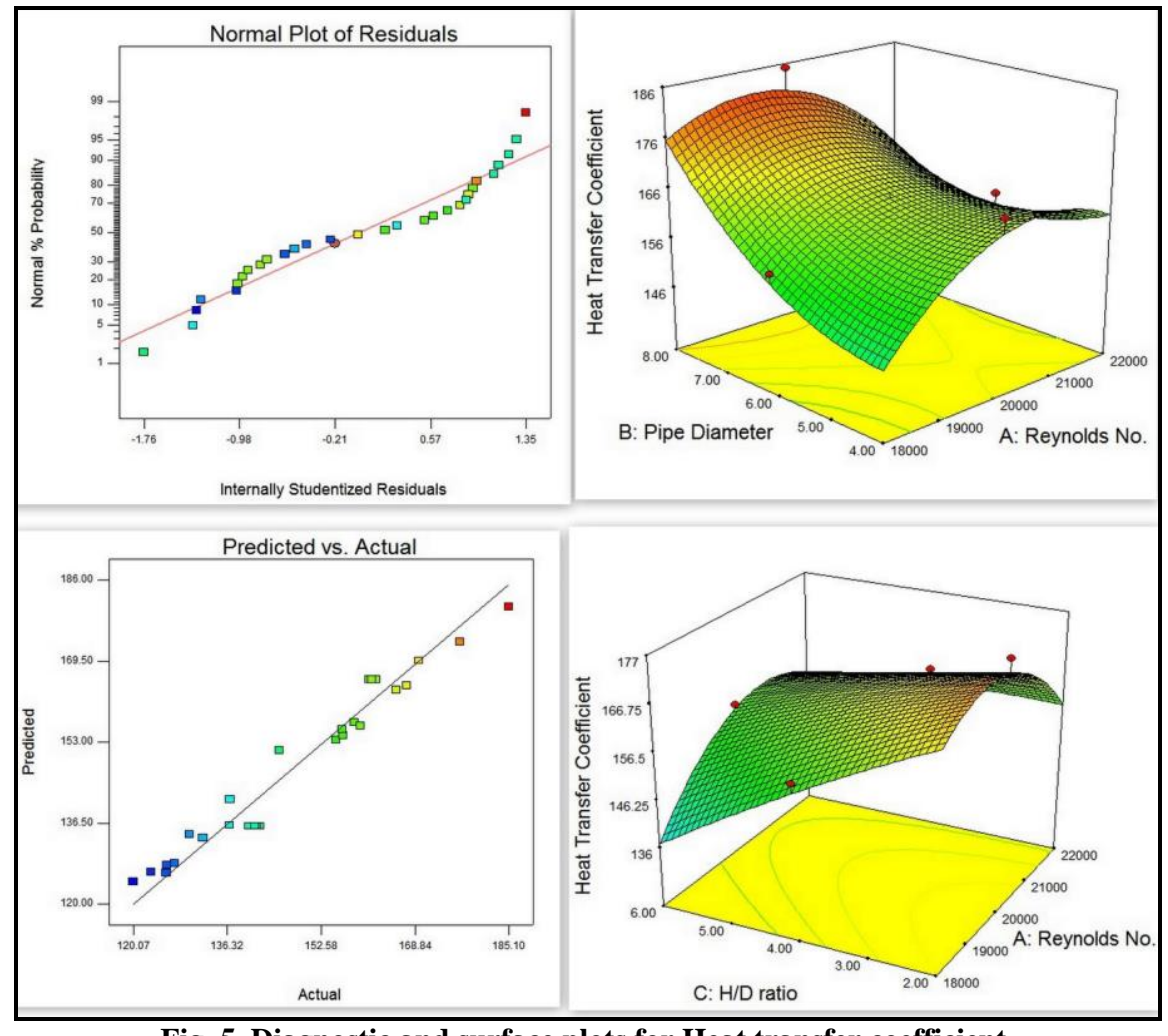

Fig. 5. Diagnostic and surface plots for Heat transfer coefficient. 
P. Chandramohan et al. / JAFM, Vol. 14, No. 1, pp. 131-145, 2021.

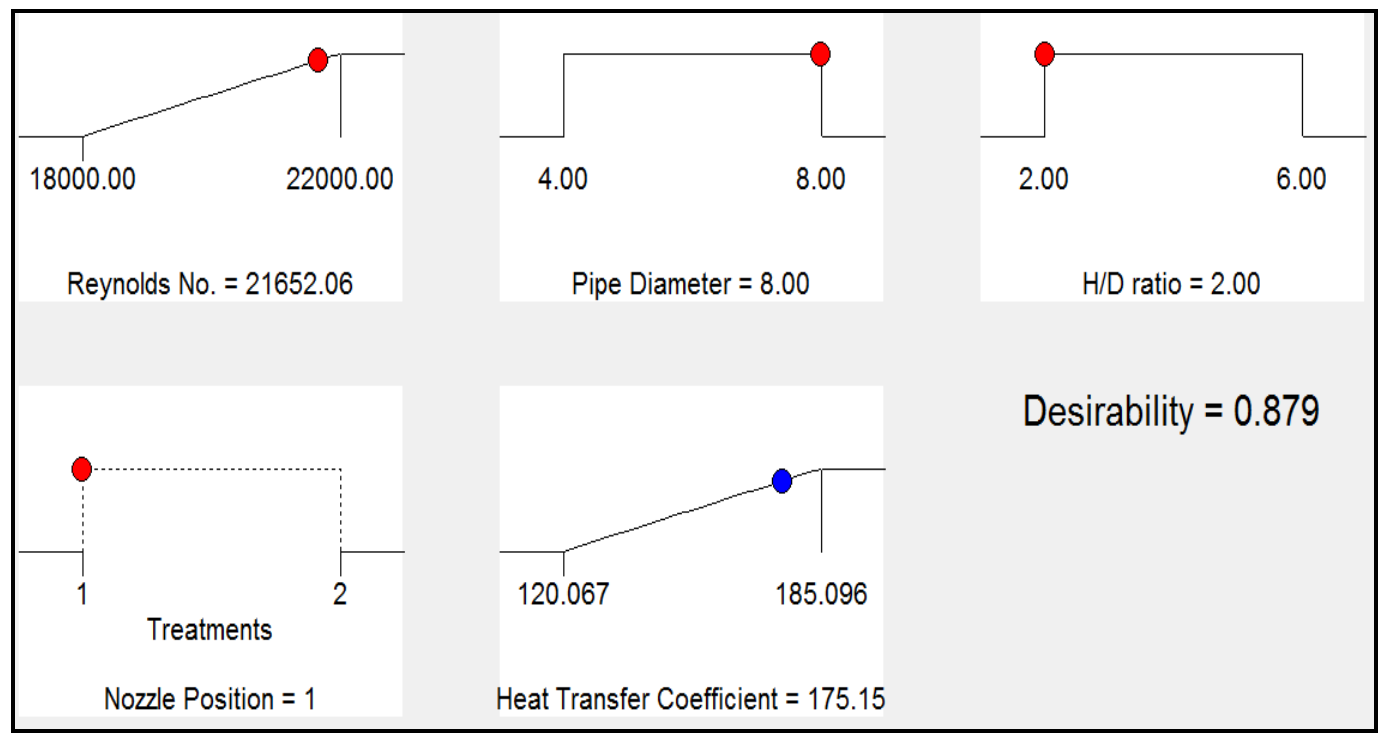

Fig. 6. Numerical optimization of Heat transfer coefficient.

Table 5 ANOVA for Temperature

\begin{tabular}{|c|c|c|c|c|c|c|}
\hline Source & SS & Dof & MSS & F Value & Prob $>$ F & $\%$ Contribution \\
\hline Model & 1984.381 & 13 & 152.6447 & 31.0735 & $<0.0001$ & $96.19 \%$ \\
\hline A-Reynolds No. & 544.5222 & 1 & 544.5222 & 110.847 & $<0.0001$ & $26.39 \%$ \\
\hline B-Pipe Diameter & 56.7009 & 1 & 56.7009 & 11.54246 & 0.0037 & $2.75 \%$ \\
\hline C-H/D ratio & 169 & 1 & 169 & 34.4029 & $<0.0001$ & $8.19 \%$ \\
\hline D-Nozzle Position & 17.48033 & 1 & 17.48033 & 3.558427 & 0.0775 & $0.85 \%$ \\
\hline $\mathrm{AB}$ & 0.147267 & 1 & 0.147267 & 0.029979 & 0.8647 & $0.01 \%$ \\
\hline $\mathrm{AC}$ & 0.1176 & 1 & 0.1176 & 0.02394 & 0.8790 & $0.01 \%$ \\
\hline $\mathrm{AD}$ & 88.50901 & 1 & 88.50901 & 18.01756 & 0.0006 & $4.29 \%$ \\
\hline $\mathrm{BC}$ & 33.84375 & 1 & 33.84375 & 6.889487 & 0.0184 & $1.64 \%$ \\
\hline $\mathrm{BD}$ & 1.7328 & 1 & 1.7328 & 0.352742 & 0.5609 & $0.08 \%$ \\
\hline $\mathrm{CD}$ & 0.282133 & 1 & 0.282133 & 0.057433 & 0.8136 & $0.01 \%$ \\
\hline $\mathrm{A}^{2}$ & 49.69227 & 1 & 49.69227 & 10.11573 & 0.0058 & $2.41 \%$ \\
\hline $\mathrm{B}^{2}$ & 16.57865 & 1 & 16.57865 & 3.374873 & 0.0848 & $0.80 \%$ \\
\hline $\mathrm{C}^{2}$ & 85.59842 & 1 & 85.59842 & 17.42505 & 0.0007 & $4.15 \%$ \\
\hline Residual & 78.59802 & 16 & 4.912376 & - & - & $3.81 \%$ \\
\hline Lack of Fit & 75.92482 & 8 & 9.490602 & 28.40222 & $<0.0001$ & $3.68 \%$ \\
\hline Pure Error & 2.6732 & 8 & 0.33415 & - & - & $0.13 \%$ \\
\hline Cor Total & 2062.979 & 29 & - & - & - & $100.00 \%$ \\
\hline Std. Dev. & 2.216388 & & $\mathrm{R}^{2}$ & 0.961901 & - & - \\
\hline Mean & 73.67333 & & Adjusted $\mathrm{R}^{2}$ & 0.930945 & - & - \\
\hline C.V. \% & 3.008399 & & Predicted $\mathrm{R}^{2}$ & 0.815517 & - & - \\
\hline PRESS & 380.5848 & & Adeq Precision & 22.77178 & - & - \\
\hline
\end{tabular}


P. Chandramohan et al. / JAFM, Vol. 14, No. 1, pp. 131-145, 2021.

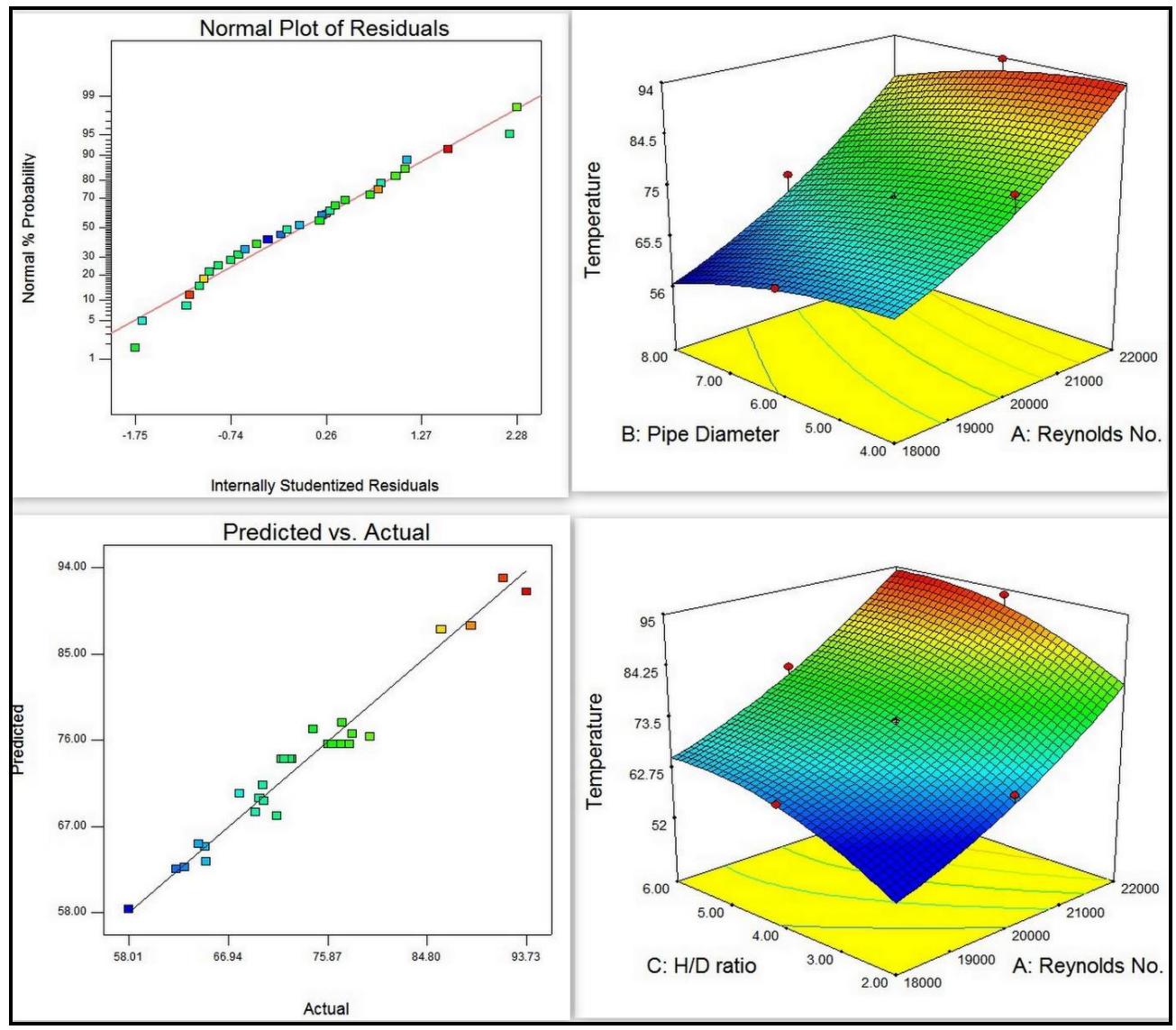

Fig. 7. Analysis of Temperature.

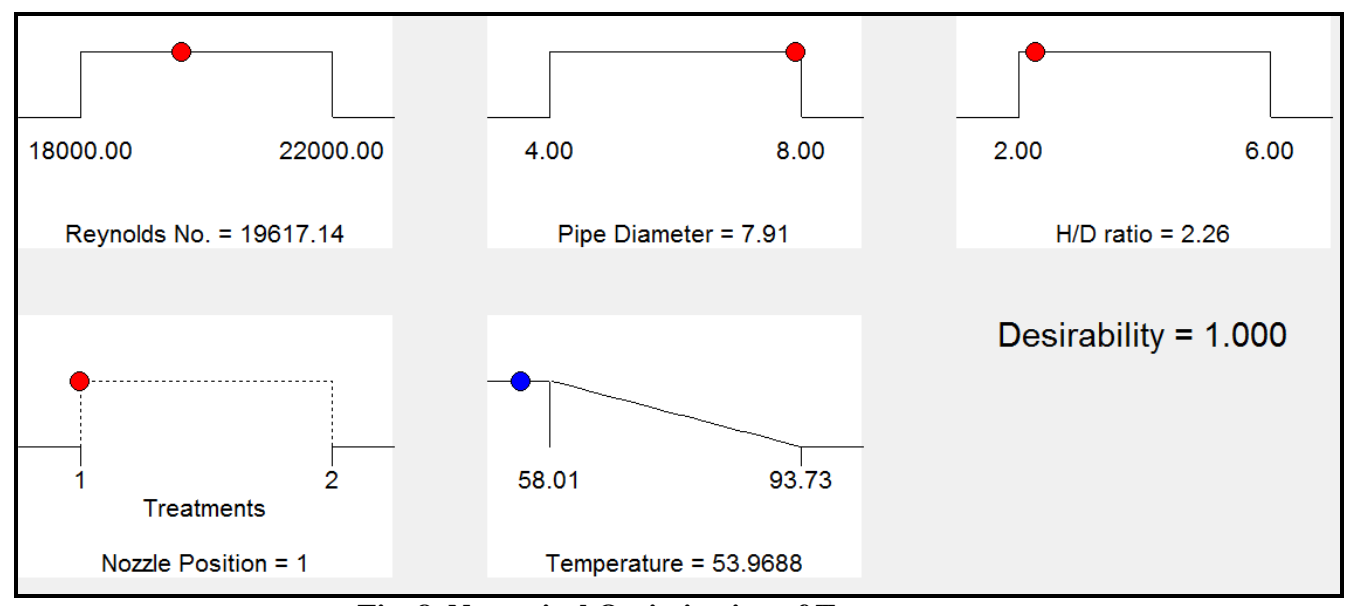

Fig. 8. Numerical Optimization of Temperature.

The residual plot of Nusselt no., predicted vs. actual values and surface plots are shown in Fig. 9. It is inferred from the plot that the remnant are spread sparingly along the fitted unswerving line between the forecast and experimental Nusselt no., following a normal distribution. The surface plot drawn between the Reynolds no. and pipe diameter shows that Nusselt no. varies linearly with elevation in Reynolds no., which also increases exponentially with elevation in pipe diameter. Surface plot drawn in between $\mathrm{Re}$ and $\mathrm{H} / \mathrm{D}$ ratio shows a relationship between H/D ratio and heat transfer coefficient.
Maximum Nusselt no. is desirable for optimization purpose and hence higher the better option is chosen during numerical procedure of optimization. With

that, the optimum condition achieved is Reynolds No. of 20671, pipe diameter of $8 \mathrm{~mm}, \mathrm{H} / \mathrm{D}$ ratio of 2.25 and in-line nozzle position. The predicted value of Nusselt no. is 28.86 with a higher desirability value of 1, as presented in Fig. 10.

The developed mathematical models using Design Expert Software with a coded unit as given in Eq. 
P. Chandramohan et al. / JAFM, Vol. 14, No. 1, pp. 131-145, 2021.

Table 6 ANOVA for Nusselt Number

\begin{tabular}{|c|c|c|c|c|c|c|}
\hline Source & SS & DoF & MSS & F Value & Prob $>F$ & $\%$ Contribution \\
\hline Model & 209.2879 & 13 & 16.09907 & 35.09673 & $<0.0001$ & $96.61 \%$ \\
\hline A-Reynolds No. & 3.182414 & 1 & 3.182414 & 6.937814 & 0.0180 & $1.47 \%$ \\
\hline B-Pipe Diameter & 19.94567 & 1 & 19.94567 & 43.4825 & $<0.0001$ & $9.21 \%$ \\
\hline C-H/D ratio & 13.42897 & 1 & 13.42897 & 29.27578 & $<0.0001$ & $6.20 \%$ \\
\hline D-Nozzle Position & 14.12219 & 1 & 14.12219 & 30.78705 & $<0.0001$ & $6.52 \%$ \\
\hline $\mathrm{AB}$ & 1.018807 & 1 & 1.018807 & 2.221048 & 0.1556 & $0.47 \%$ \\
\hline $\mathrm{AC}$ & 2.646678 & 1 & 2.646678 & 5.769884 & 0.0288 & $1.22 \%$ \\
\hline $\mathrm{AD}$ & 4.51398 & 1 & 4.51398 & 9.84069 & 0.0064 & $2.08 \%$ \\
\hline $\mathrm{BC}$ & 10.80165 & 1 & 10.80165 & 23.54811 & 0.0002 & $4.99 \%$ \\
\hline $\mathrm{BD}$ & 0.339031 & 1 & 0.339031 & 0.739105 & 0.4026 & $0.16 \%$ \\
\hline $\mathrm{CD}$ & 13.47748 & 1 & 13.47748 & 29.38153 & $<0.0001$ & $6.22 \%$ \\
\hline $\mathrm{A}^{2}$ & 0.121815 & 1 & 0.121815 & 0.265562 & 0.6134 & $0.06 \%$ \\
\hline $\mathrm{B}^{2}$ & 21.46602 & 1 & 21.46602 & 46.79693 & $<0.0001$ & $9.91 \%$ \\
\hline $\mathrm{C}^{2}$ & 1.168711 & 1 & 1.168711 & 2.547845 & 0.1300 & $0.54 \%$ \\
\hline Residual & 7.33929 & 16 & 0.458706 & - & - & $3.39 \%$ \\
\hline Lack of Fit & 6.379551 & 8 & 0.797444 & 6.647175 & 0.0074 & $2.94 \%$ \\
\hline Pure Error & 0.959739 & 8 & 0.119967 & - & - & $0.44 \%$ \\
\hline Cor Total & 216.6271 & 29 & - & - & - & $100.00 \%$ \\
\hline Std. Dev. & 0.677278 & - & $\mathrm{R}^{2}$ & 0.96612 & - & - \\
\hline Mean & 23.40722 & - & Adjusted $\mathrm{R}^{2}$ & 0.938593 & - & - \\
\hline C.V. \% & 2.893459 & - & Predicted $\mathrm{R}^{2}$ & 0.764786 & - & - \\
\hline PRESS & 50.95372 & - & Adeq Precision & 24.51561 & - & - \\
\hline
\end{tabular}

$$
\begin{aligned}
H T C= & -907.684+0.106657 \times \operatorname{Re}+21.02201 \times D-32.1253 \times H / D \\
& -0.00163 \times \operatorname{Re} \times D+0.001861 \times \operatorname{Re} \times H / D-1.17631 \times D \times H / D \\
& -2.6 E^{-6} \times \operatorname{Re}^{2}+1.697548 \times D^{2}-0.31389 \times H / D^{2} \\
T e m p t= & 237.9441-0.02419 \times \operatorname{Re}-1.46912 \times D+5.0235 \times H / D \\
+ & 5.88 \mathrm{E}^{-5} \times \operatorname{Re} \times D+5.25 E^{-5} \times \operatorname{Re} \times H / D+0.890625 \times D \times H / D \\
& +7.71 \mathrm{E}^{-7} \times \operatorname{Re}^{2}-0.44507 \times D^{2}-1.01132 \times H / D^{2}
\end{aligned}
$$

$$
\begin{aligned}
& -0.00015 \times \operatorname{Re} \times D-0.00025 \times \operatorname{Re} \times H / D+0.503154 \times D \times H / D \\
& -3.8 E^{-8} \times \operatorname{Re}^{2}+0.506446 \times D^{2}+0.118171 \times H / D^{2}
\end{aligned}
$$

$H T C=-923.802+0.105669 \times \operatorname{Re}+21.28459 \times D-31.0102 \times H / D$

$-0.00163 \times \operatorname{Re} \times D+0.001861 \times \operatorname{Re} \times H / D-1.17631 \times D \times H / D$

$-2.6 E^{-6} \times \operatorname{Re}^{2}+1.697548 \times D^{2}-0.31389 \times H / D^{2}$

Tempt $=292.1208-0.02691 \times \operatorname{Re}-1.08912 \times D+4.870172 \times H / D$

$$
\begin{aligned}
& +5.88 \mathrm{E}^{-5} \times \operatorname{Re} \times D+5.25 E^{-5} \times \operatorname{Re} \times H / D+0.890625 \times D \times H / D \\
& +7.71 \mathrm{E}^{-7} \times \operatorname{Re}^{2}-0.44507 \times D^{2}-1.01132 \times H / D^{2}
\end{aligned}
$$

Nusselt No. $=-19.4499+0.004202 \times \operatorname{Re}-3.96697 \times D-0.630684 \times H / D$

$$
\begin{aligned}
& -0.00015 \times \operatorname{Re} \times D-0.00025 \times \operatorname{Re} \times H / D+0.503154 \times D \times H / D \\
& -3.8 E^{-8} \times \operatorname{Re}^{2}+0.506446 \times D^{2}+0.118171 \times H / D^{2}
\end{aligned}
$$




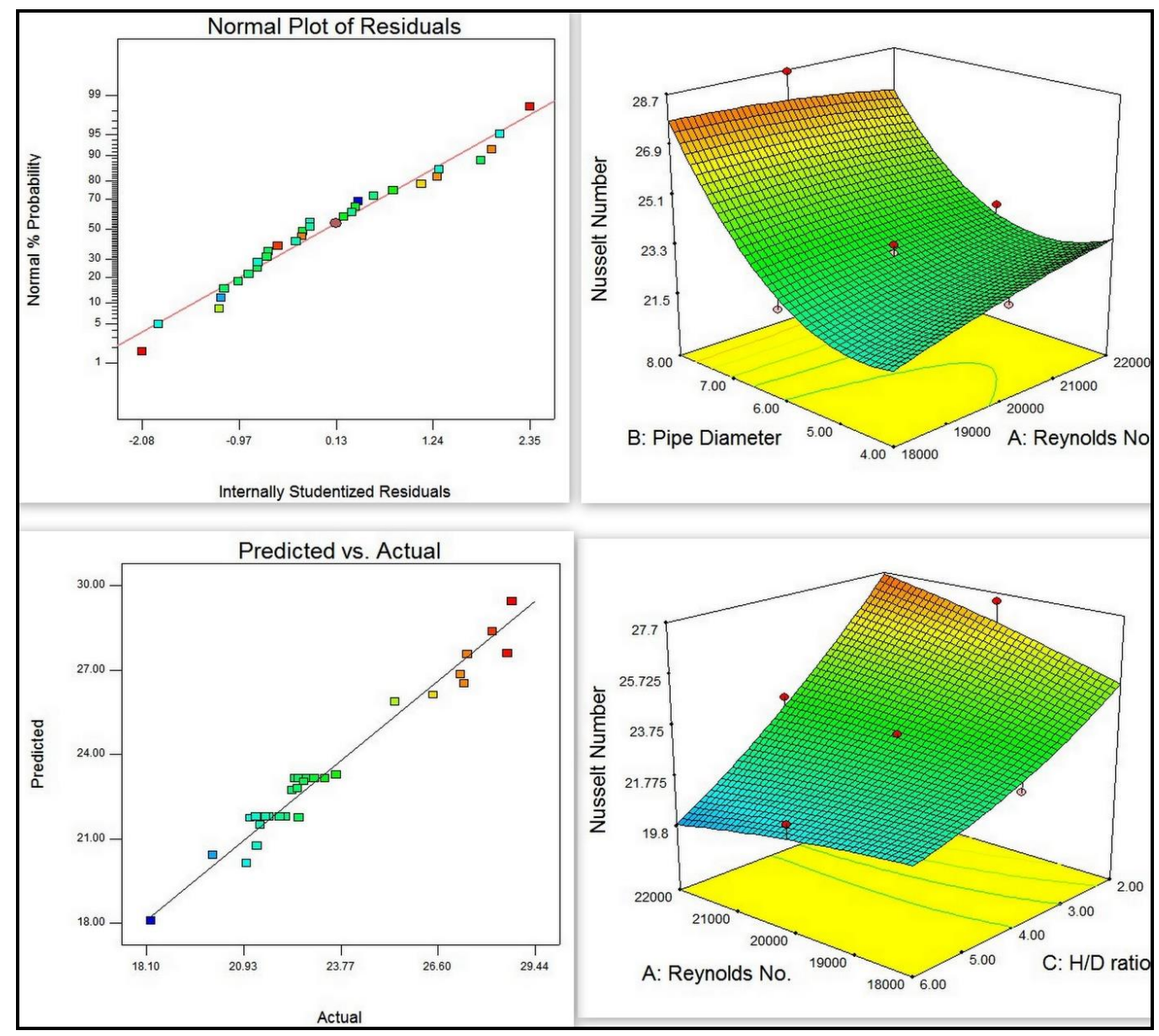

Fig. 9. Analysis of Nusselt number.

(5) to (10) are used to predict the Nusselt Number, coefficient of heat transfer and temperature for inline as well as staggered positions of nozzle. The second order Regression models for In-Line Nozzle positions are presented in Eq. (3), Eq. (4) and in Eq. (5). Similarly, the second order Regression models for Staggered Nozzle positions are presented in Eq. (6), Eq. (7) and in Eq. (8).

\subsection{Desirability Analysis}

Analysis of some responses is involved in many response surface problems. In this work, three responses were measured. Concomitant contemplation of multifarious responses involves culmination of a suitable response surface model for every response initially after which it observes all conditions that additionally optimizes multiple responses within desired ranges (Gajalakshmi et al. 2019). The simultaneous optimization technique by desirability functions is a useful approach for optimization of multifarious responses. Individual desirability function is converted from each response that varies over the range is the general approach

$$
0 \leq d_{i} \leq 1
$$

Where $d_{i}=1$, then the response $y$ is considered to be at its goal or target and if $d_{i}=0$, the output is considered to be exterior to region of an acceptance. Then in order to maximize the gross desirability the design variables are chosen, here heat transfer coefficient is set to maximum, temperature as minimum and Nusselt no. to maximum to optimize the chosen input parameters. The desired desirability value of 1 is achieved during the multiresponse optimization (Deepanraj et al. 2020). The optimum condition evolved is Reynolds No. of 20279, pipe diameter of $7.93 \mathrm{~mm}, \mathrm{H} / \mathrm{D}$ ratio of 2.1 and in-line nozzle position. The predicted value of HTC is $189.627 \mathrm{~W} / \mathrm{m}^{2} \mathrm{~K}$, temperature of $57.15^{\circ} \mathrm{C}$ and Nusselt no. of 28.78 . Figure 11 shows the ramp plot of the multi-objective desirability analysis with the optimum values and predicted responses.

Bar graph and cube plot of all the responses during the multi-objective optimization is given in Fig. 12. It is observed that a gross desirability value of 1 is attained along the individual desirability value of 1 , which is highly acceptable.

Cube plot of the chosen inputs and the desirability value shown in figure implies the combination of input variables and the corresponding desirability values for all the three inputs. Figure 13 shows the contour and surface plots of desirability over the combination of input variables. In the analysis of 


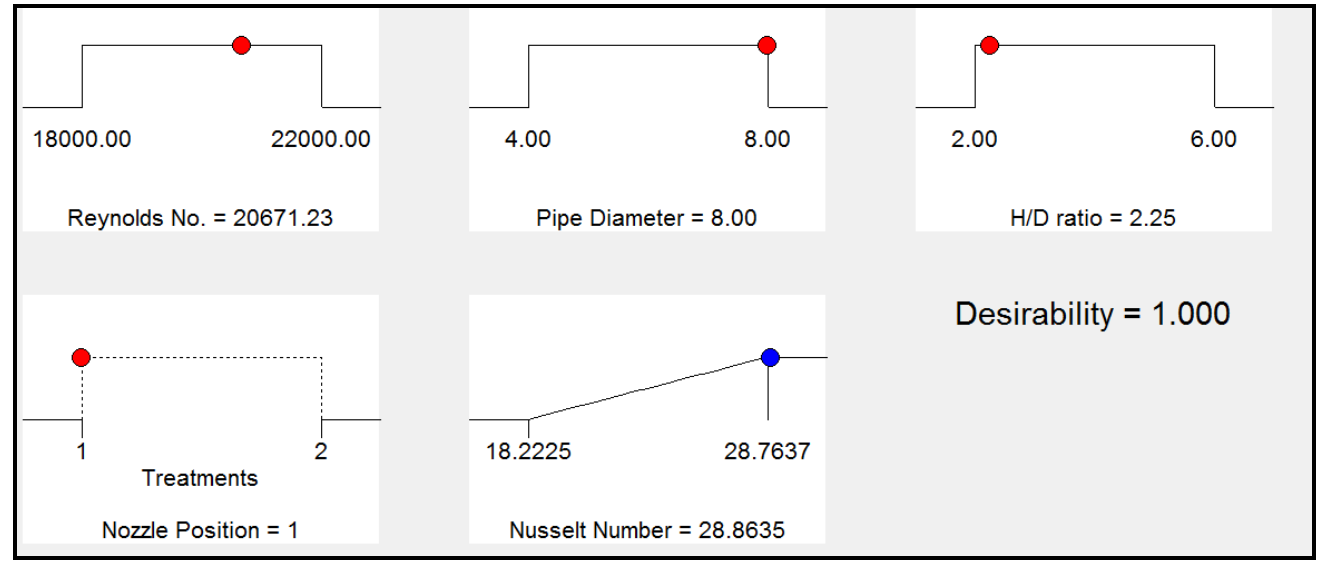

Fig. 10. Numerical optimization of Nusselt number.

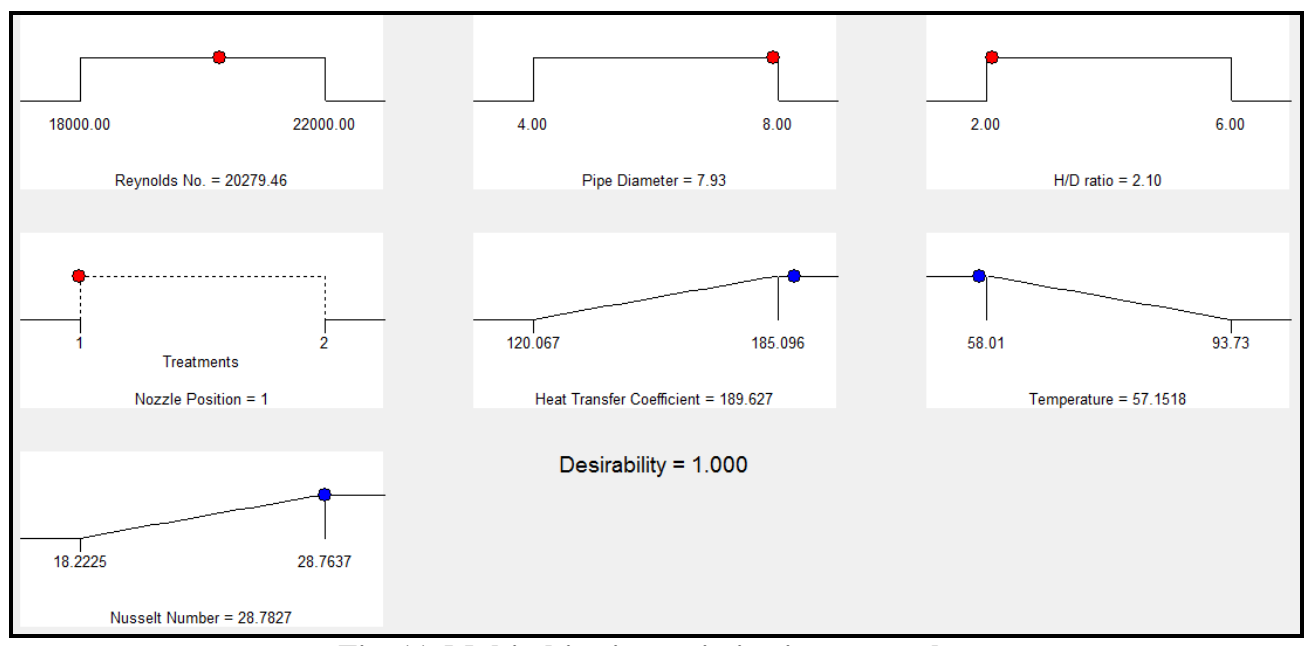

Fig. 11. Multi-objective optimization ramp plot.

the response surface a very important role is been played by contour plot. By creating contour plots for response surface analysis, it is possible to characterize the surface shape and locate the optimum with acceptable precision. In the contour plot between Re and pipe diameter, the contour plot and response surface illustrate a saddle point (or minimax) condition, whereas in between the Reynolds no. and H/D ratio, the response surface and contour plot illustrate a surface with a minimum condition. It is obvious that when the Reynolds no. increases desirability increases exponentially and with increase in pipe diameter, desirability increases linearly but reduction in desirability is visualized with elevation of $\mathrm{H} / \mathrm{D}$ ratio.

With the identified optimum input values, performance of confirmation experiment is done to verify results and thus the determined experimental values are given in Table 7 and the \% error is calculated between the software predicted and the real time experimental results. The maximum error obtained is 3.64 , which proves that the results are much closer to the values that are values thereby proving superiority of this desirability analysis for multi-objective optimization.

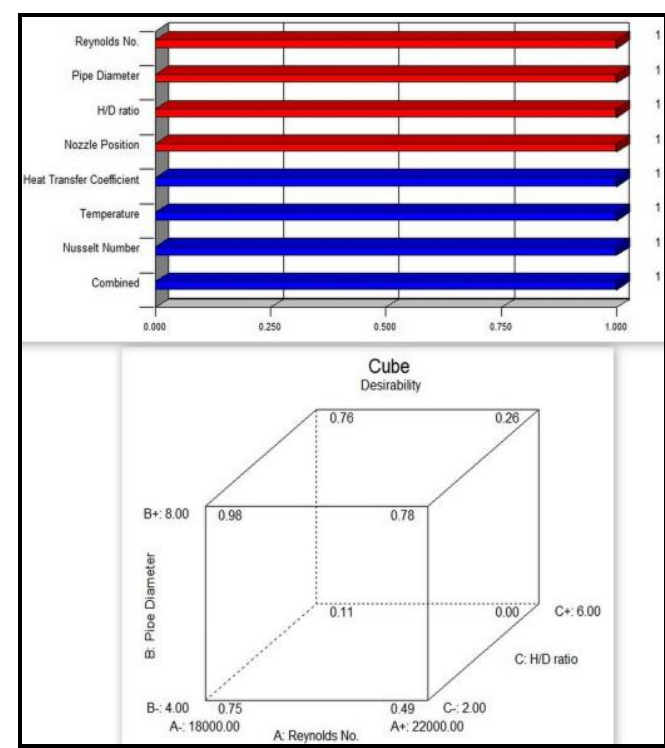

Fig. 12. Bar graph and cube of desirability analysis. 


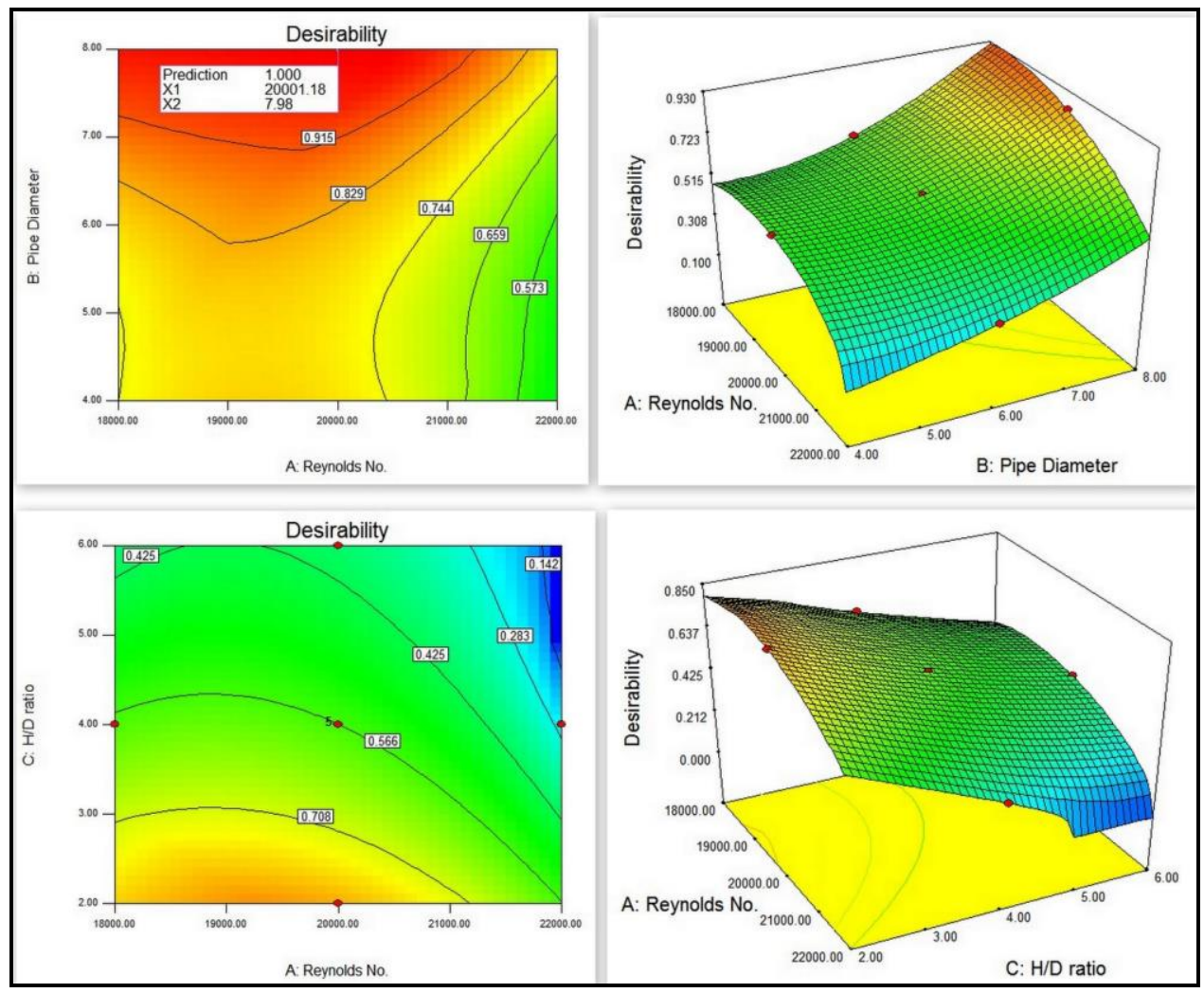

Fig. 13. Contour and Surface plot for desirability.

Table 7 Comparison of predicted and experimental values

\begin{tabular}{|c|c|c|c|}
\hline Response & Prediction & $\begin{array}{c}\text { Experiment } \\
\text { al }\end{array}$ & $\%$ Error \\
\hline $\begin{array}{c}\text { Heat Transfer } \\
\text { Coefficient }\end{array}$ & 189.796 & 191.27 & -0.78 \\
\hline Temperature & 57.0786 & $\begin{array}{c}59.157 \\
3\end{array}$ & -3.64 \\
\hline Nusselt Number & 28.8526 & 28.5184 & 1.16 \\
\hline
\end{tabular}

\section{CONCLUSION}

In this analysis, multi-objective optimization of temperature, heat transfer coefficient Nusselt no. is performed using RSM on the basis of desirability analysis and the conclusions arrived are as follows.

1. With change in nozzle position, improved heat transfer coefficient and Nusselt no. can be achieved with lowering the temperature at the flat plate using multiple jet air cooling system.

Desirability technique is applied to optimize the output responses and the optimum condition evolved is Reynolds No. of 20279, pipe diameter of $7.93 \mathrm{~mm}, \mathrm{H} / \mathrm{D}$ ratio of 2.1 and in-line nozzle position. The predicted value of heat transfer coefficient is $189.627 \mathrm{~W} / \mathrm{m}^{2} \mathrm{~K}$, temperature of $57.15^{\circ} \mathrm{C}$ and Nusselt no. of 28.78 .

2. A lower error present amid the predicted and experimental outputs, proving the supremacy of this technique.

3. With increasing pipe diameter, heat transfer coefficient, Nusselt no. increases with reduction in temperature.

4. With increase in Reynolds no. temperature decreases both for Nusselt no. and normalized heat transfer coefficient, whereas temperature increases initially and then declines with further increase in Re.

5. With elevation in H/D ratio, the temperature increases drastically but Nusselt no. and normalized heat transfer coefficient reduces first and increases for 6D.

6. When the nozzle position is inline, temperature is lower but Nusselt no. and normalized heat transfer coefficient is no higher.

\section{REFERENCES}

Bahrampoury, R., A. Behbahaninia, A. Shadaram and E. Taghdiri (2009). Comparison between In-line and Staggered Arrangements in Heat Recovery Steam Generators. Proceedings of the Fourth International Exergy, Energy and Environment Symposium April 19-23, AUS, Sharjah, UAE.

Brizzi, E. L., A. Bernard, J. L. Bousgarbies, E. Doringnac and J. J. Vullierme (2000). Study of Several Impinging Jets. Journal of Thermal Science 9(3), 217-223. 
Caggese, O., G. Gnaegi, G. Hannema and A. Terzis (2013). Peter Ott, Experimental and numerical investigation of a fully confined impingement round jet, International Journal of Heat and Mass Transfer 65, 873-882.

Chandramohan, P., S. N. Murugesan and S. Arivazhagan (2017). Heat Transfer Analysis of Flat Plate Subjected To Multi-Jet Air Impingement Using Principal Component Analysis and Computational Technique. Journal of Applied Fluid Mechanics 10(1), 293-306.

Chandramohan, P., S. N. Murugesan and S. Arivazhagan (2019). Experimental Investigation and CFD Analysis of Influence of Swirl, Arrangement of Nozzle, Cross Section And Diameter of Jets on Heat Transfer in Multi-Jet Air Impingement Cooling. Thermal Science 23(3B), 2025-2035.

Chougule, N. K., G. V. Parishwad, P. R. Gore, S. Pagnis and S. N. Sapali (2011). CFD Analysis of Multi-jet Air Impingement on Flat Plate, Proceedings of the World Congress on Engineering 2011, III WCE 2011, July 6 - 8, London, U.K.

Deepanraj, B., N. Senthilkumar, J. Ranjitha, S. Jayaraj and H. C. Ong (2020). Biogas from food waste through anaerobic digestion: optimization with response surface methodology, Biomass Conversion and Biorefinery DOI: 10.1007/s13399-020-006469.

Fechter, S., A. Terzis, P. Ott, B. Weigand, J. V. Wolfersdorf and M. Cochet (2013). Experimental and numerical investigation of narrow impingement cooling channels, International Journal of Heat and Mass Transfer 67, 1208-1219.

Fenot, M., J. J. Vullierme and E. Dorignac (2005). Local heat transfer due to several configurations of circular air jets impinging on a flat plate with and without semi-confinement. International Journal of Thermal Sciences 44, 665-675.

Gajalakshmi, K., N. Senthilkumar, B. Prabu (2019). Multi-response Optimization of Dry Sliding Wear Parameters of AA6026 Using Hybrid Grey Relational Analysis Coupled with Response Surface Method. Measurement and Control 52(5-6), 540-553.

Gamst, G., S. M. Lawrence and A. J. Guarino (2008). Analysis of Variance Designs - A Conceptual and Computational Approach with SPSS and SAS. Cambridge University Press, Cambridge, U.K.

Hosain, Md L., R. B. Fdhila and A. Daneryd (2014). Multi-Jet Impingement Cooling of a Hot Flat Steel Plate. Energy Procedia 61, 1835 -1839 .

Huang, L. and M. S. EI-Genk (1998). Heat transfer and flow visualization experiments of swirling, multi-channel, and conventional impinging jets. International Journal Heat Mass Transfer $41,583-600$

Husain, A., S. M. Kim and K. Y. Kim (2013). Performance analysis and design optimization of micro-jet impingement heat sink. Heat Mass Transfer49, 1613-1624.

Indira Priya, P., P. Chandramohan and A. Kannan (2018). Fuzzy logic approach for temperature analysis in multi-jet air impingement investigation. Romanian Journal of Information Science and Technology 21(4), 406-428.

Kim, S. M. and K. Y. Kim (2016). Evaluation of cooling performance of impinging jet array over various dimpled surfaces. Heat Mass Transfer 52, 845-854.

Martin, H. (1977). Heat and mass transfer between impinging gas jets and solid surfaces, Advances in Heat Transfer 13, 1- 60.

Meslem, A., V. Sobolik, F. Bode, K. Sodjavi, Y. Zaouali and I. Nastase (2013). Flow dynamics and mass transfer in impinging circular jet at low Reynolds number. Comparison of convergent and orifice nozzles. International Journal Heat Mass Transfer 67, 25-45.

Montgomery, D. C. (2013). Design and Analysis of Experiments. John Wiley \& Sons, Inc., USA.

Negi, D. S. and A. Pattamatta (2015) Profile shape optimization in multi-jet impingement cooling of dimpled topologies for local heat transfer enhancement. Heat Mass Transfer 51, 451464.

Sagot, B., G. Antonini, A. Christgen and A. F. Burona (2008). Jet impingement heat transfer on a flat plate at a constant wall temperature. International Journal of Thermal Sciences 47, 1610-1619.

Senthilkumar, N. and T. Tamizharasan (2015). Flank Wear and Surface Roughness prediction in Hard Turning via Artificial Neural Network and Multiple Regressions. Australian Journal of Mechanical Engineering 13(1), 31-45.

Senthilkumar, N., C. K. Dhinakarraj, B. Deepanraj, N. Manikandan Babu and A. Santhosh Kumar (2012). Modification and Analysis of Compressor Inter-Cooler Fin in Turbocharger using FEM. Procedia Engineering 38, 379384.

Senthilkumar, N., T. Tamizharasan and S. Gobikannan (2014a). Application of Response Surface Methodology and Firefly Algorithm for optimizing Multiple Responses in Turning AISI 1045 Steel. Arabian Journal for Science and Engineering 39(11), 8015-8030.

Senthilkumar, N., T. Tamizharasan and V. Anandakrishnan (2014b). Experimental Investigation and Performance Analysis of Cemented Carbide Inserts of different 
P. Chandramohan et al. / JAFM, Vol. 14, No. 1, pp. 131-145, 2021.

geometries using Taguchi based Grey Relational Analysis. Measurement 58, 520536.

Sharif, M. A. R. (2013) Heat transfer from an isothermally heated flat surface due to twin oblique slot-jet impingement, Procedia Engineering 56, 544 - 550.

Singh, D., B. Premachandran and S. Kohli (2013) Experimental and numerical investigation of jet impingement cooling of a circular cylinder. International Journal of Heat and Mass Transfer 60, 672-688.

Srivalli, G., B. Raghavarao, M. R. Ch. Sastry (2012). Fluid flow and heat transfer analysis of laminar multiple square jets impinging on a flat plate. International Journal of Engineering Research and Applications 2, 48-56.

Tripathi, A. and A. K. Singh (2015). A Review On Heat Transfer And Pressure Drop Correlations In Solid Circular Finned Tube Bundles Positioned At Inline And Staggered Arrangement In Cross Flow. International Journal of Research In Aeronautical and Mechanical Engineering 3(3), 61-67.
Wang, H., W. Yu and Q. Cai (2012). Experimental study of heat transfer coefficient on hot steel plate during water jet impingement cooling, Journal of Materials Processing Technology $212,1825-1831$

$\mathrm{Xu}$, F. and M. S. Gadala (2006). Heat transfer behavior in the impingement zone under circular water jet. International Journal of Heat and Mass Transfer 49(1), 3785-3799.

Yang, W., X. Li and X. Liu (2013). An investigation on the cooling characteristics of impingement-reversed convection film cooling in a curved section. Journal of Mechanical Science and Technology 27(5), 1509-1517.

Zhang, L. W., S. Balachandar, D. K. Tafti and F. M. Najjar (1997) Heat transfer enhancement mechanisms in inline and staggered parallelplate fin heat exchangers. International Journal of Heat and Mass Transfer 40(10), 2307-2325.

Zhu, D. M., Y. T. Wang and J. H. Zhu (2014). Heat Transfer Characteristics of Multinozzle Air Impingement Jet during Die Steel Plate Cooling Progress. Advances in Mechanical Engineering, Article ID 698072. 